\title{
The Ph.D. in Library Science
}

This article outlines some of the opportunities in libraries for holders of the Ph.D. degree, particularly degrees taken in specialties which did not exist ten or fifteen years ago. It is argued that the field is now much more attractive for the specialist in Library Science. At the same time, it is suggested that a research degree is not necessary for administrative librarians, though a doctorate of a different kind may be desirable.

A NYONE WHO HAS STRUGGLED through the process of obtaining a $\mathrm{Ph} . \mathrm{D}$. degree certainly would agree that it was a most vigorous experience. Very few people find it sufficiently untraumatic to go through it more than once. Graduate students are full of ideas for making the experience more meaningful-an uncritical graduate student is an anomalybut these ideas have a strong tendency to vanish once the sheepskin is in hand.

The Ph.D. in Library Science (or Library Service or Library-and-Information-Science or what have you-the broadest sense is intended throughout this paper) is, comparatively speaking, a relatively new degree. For this reason a number of the faculty in library schools have taken their Ph.D. degrees in subject fields. Library science as a subject field in itself has not been so clearly defined as the more traditional fields, such as history, mathematics, psychology and so forth. Just what constitutes library science? It includes the standard subdivisions of cataloging, classification, reference, bibliography, book selection; it has also been extended to include information science (née documentation), some aspects of computer science, behavioral

Mrs. Richmond is a Professor in the School of Library Science at Case Western Reserve University. science, and anything else that seems applicable.

The upshot is that library science is a conglomerate of eclectic subjects. Moreover this conglomerate sprawls all over the field of knowledge, judging from the variety of dissertation topics and master's essays accepted. The eclecticism has been free and unlimited, particularly during the past decade.

Upon contemplation, this is not as bad as it sounds. Consider the variety of work in the library field. There is a place for everyone from the accountant to the group social worker, from historical bibliographer to architect, from linguist to chemist. Positions requiring subject competence not necessarily limited to bookcentered activities are found in almost every major library. For many of these positions a dual master's degree is a minimum requirement and a subject Ph.D. almost a necessity. The "bookman" is not the only type of librarian.

So where then does the Ph.D. in library science fit in? Is there a need for a specialist in library science at the Ph.D. level? Why a Ph.D. in library science at all? What will this person do that a subject specialist cannot do? (Or perhaps one should ask, what will this person do that a subject specialist cannot do better?) Should we not continue to make do with converts from other fields? What 
special competence should a Ph.D. in library science command? Is only one area suitable for a Ph.D., or, like history, should one concentrate on groups, with major strength in one or two, and minor strength in two or three others, out of a choice of fifteen to twenty groups? Has the field of library science grown sufficiently to tolerate or even encourage a variety of Ph.D.'s as is the case with regular academic subjects? The answer to these questions may clarify the quo vadis involved in the development of Ph.D. programs.

Some twelve years ago, this writer published a paper on "The Subject Ph.D. and Librarianship." ${ }^{1}$ Since then, the whole field of library science has changed, so that the mere possession of a Ph.D. degree in a subject field does not by itself qualify a person for many of the new areas which have opened up. Almost all of the early Ph.D.'s in library science went into administration or teaching. This is still the case in many instances, but the development of specialties in the library and the need for trained specialists to fill these positions have presented opportunities for those holders of the doctorate who are scholars and who wish to pursue scholarly interests instead of being bogged down in administration. In the past, it has been no help to the intellectual aspects of library science to have the most able personnel in the field tied up in administration when their talents were so badly needed in advancing the frontiers of the field itself.

Turning to teaching on the part of many of the earlier Ph.D.'s has been a necessity. Some graduates have wisely mixed teaching with practical experience, to the improvement of both. So far, versatility has been the hallmark of Ph.D.'s in library science.

The presence of specialist positions in major libraries offers hope that library science at last will begin to develop in its own right, and that the late twentieth century may again see a flowering of ideas, theories, and general progress in librarianship such as graced the last quarter of the nineteenth century.

What are the specialties now beginning to be supported in the libraries of the country? Here is a partial listing:

Bibliographer

Building Plans Specialist

Cataloging-Reference Subject Specialist

Communications Specialist

Information Systems Specialist

Media Specialist

Network Coordinator

Management Specialist

Rare Books (Special Collections, Archives) Specialist

Technical Information Specialist

Research Specialist

Library Education Specialist

Undoubtedly more could be added. Some of these fields already have enough substance to support a Ph.D. program and enough content to interest a scholar who wishes to devote his life's work to it. Thus the answer to our first question, "Where does the Ph.D. in library science fit in?" can be answered by citing the above twelve specialist fields, as a starter. No longer is the holder of the doctorate limited to administration and teaching, a factor that should attract many able candidates.

However, there is a little more to the picture than this. Each of the above specialties requires expert knowledge of another subject field (or fields) besides library science. The Ph.D. limited only to library science disciplines will not qualify for these positions. The base for the Ph.D. must be broad enough to allow for collateral lines of study. Thus the Ph.D. program recently begun at Syracuse University will turn out a Communications Specialist (Information Transfer). Other programs elsewhere will turn out other kinds of specialists. 
The reason subject Ph.D.'s are being used in specialist positions in libraries is that library science programs to date have tended to be too narrow. This means that the library school will have to develop good cooperative relationships with other departments of the graduate school so that the library specialists will be trained to competence in both the subject area and library science. This is preferable to bringing subject specialists into the library school to teach a watered-down version of their fields according to what they think is palatable to librarians and information scientists. One runs the risk of losing good students to the subject field, but it is better to teach the subject per se and library science per se and to help the student bridge the gap in his own head via a general seminar or through his choice of dissertation topic, than to turn out a graduate who cannot hold his own in the subject field in which he proposes to be a specialist. It is all a matter of balance.

The point is easier to see if considered in terms of library science courses taught to nonlibrarians. A course cannot go "cultural" (as is the case with courses in physics or mathematics for people who are not going to major in the subject) and still retain its full vigor for training specialists. There is a need for specialists in libraries at the Ph.D. level, provided this person is a specialist both in the subject and in library science. At this time, it is suggested that the course work would produce levels of competence in both areas, while the dissertation topic would be chosen carefully to unite the two, centering on themes which are unique to the type of speciality selected.

The specialist with the Ph.D. in library science should be competent in at least one of the various areas of that science now lacking in the subject specialist, especially the subject specialist without a library degree. In other words, what is proposed here is to take back the specialties in the library field from the nonlibrarians. The doctorate suggested here is a hybrid, and its value lies in its hybrid features-in the erudition of its holder both in the subject and in library science. It is, in effect, equivalent to the present "scientist oriented to bibliography," or "psychologist or sociologist oriented to epistemology via audiovisual media," but with the coin reversed so that the emphasis would become "bibliographer of science" or "media specialist oriented to learning processes." The specialist who just "fell into" his specialty during the expansion of the library needs in the past fifteen years would be succeeded by one who has deliberately chosen the field and become educated in it.

There is a difference between the two. The pioneer specialist, who came into the area vicariously and learned mostly by trial and error, may not be the prototype of how the position should be filled, for he created the specialty pragmatically. This is a phenomenon of expansion, since so many specialists have independently created what is essentially the same type of position. Now the next step is to design a curriculum which will consolidate the creation and improve the product.

The fact that at least twelve specialties can be identified indicates the new breadth of the field of library science. There is a cross-fertilization process, with more scope than traditional branches of library science. One could almost consider the process as a kind of matrix in depth, with the subject fields on one side and the traditional branches on the other, and the third side is composed of the various technical features which make up the field of information science. Whether library science and information science are separate but equal or a unity with multiple branches is a moot question which will not be answered here. 
Suffice it to say that some of the newer branches of information science which grew out of but are not entirely a matter of the application of technology to bibliographic organization and procedures are very important in the specialties enumerated.

The library specialist must not only be dually educated in a subject in addition to library science, but it must be only one subject and only one branch of library science. One cannot turn out a competent subject specialist possessing just a smattering of library science, such as would be the case if a single seminar covered all areas. The library specialist must be well versed in all fields generally, to the master's degree level in both subject field and library science, but then specialized in one area of each, taken simultaneously, for depth of scholarship which is not a function of the master's degree program in either subject or library science. Presumably the two areas would be tied together by the topic of the student's dissertation. Conceivably, therefore, one might get dissertation topics as: "The development of cataloging/ classification theory as a manifestation of American cultural development in the last quarter of the nineteenth century" (cataloging/classification plus American cultural history); "Analytical and descriptive bibliography of the works of x" (bibliography and literary criticism focusing on a certain author); "Computer analysis of the index terms in certain major reference tools" (computational linguistics, indexing and reference); "The library's public in the central city" (sociology/social work and public libraries); "The library society as a pressure group" (political science and library organization).

To do such work requires depth of knowledge in both fields. In addition to the usual graduate courses and seminars offered in subject fields, there must be graduate courses and seminars in depth in library science. These are not now as evident as they should be because the present master's degree program requires so many basics in the single year devoted to it. One can obtain no depth until the basics are mastered, which throws the specialized courses into a second year in most fields, notably in classification, cataloging, bibliography, and some parts of information science. This very definitely suggests that, for the Ph.D., library science should be divided into as many discrete fields as pertain to the subject, and the student should select areas of concentration in which he wishes to be examined, as is the case in other subjects. After all, a polymer chemist does not need expert knowledge in all branches of chemistry, so why should a library specialist require generality beyond that required in the basic level of the present master's degree program? In other words, he should have the knowledge considered as fundamental to the field and presented in the master's program, and after that be permitted to specialize according to his interest. Then the library science part of the total program has a chance to include some depth, as the subject field part will do automatically when he takes the standard graduate courses in the regular graduate school.

So much for the library specialist. What about the Ph.D. for the administrator? Here one may question the value of a research degree, a scholarly degree for a person who almost certainly will find it difficult to pursue serious research of a scholarly nature. The projected Illinois plan for a doctoral degree called something other than Doctor of Philosophy might be better for the administrator. ${ }^{2}$ Such a plan could consist of three or four years of courses plus a comprehensive set of examinations rather than two or three years of courses and a dissertation. This would salvage a good many would-be Ph.D.'s who never write 
their dissertations and so never complete that part of the Ph.D. program which proves that the candidate has learned how to produce an original, scholarly piece of research.

It could be and probably will be claimed that the doctor's degree without a dissertation is a "Mickey Mouse degree," but it does not have to be. After all, one can argue that what the administrator needs most is the title of "doctor," and a broad background in all areas of library science, though he may specialize in a single type of library. He may not be required to publish as much as his nonadministrative colleagues; committee work may take the place of publication. There are all kinds of doctor's degrees, at all levels of quality, but once the diploma is in the fist, it is the actions of the person that really matter and not the kind of degree earned. A good proportion of Ph.D.'s in all fields produce little or nothing in the way of scholarly work, suggesting that the degree was obtained for reasons other than a desire for an intellectually oriented life. The Ph.D. in library science might be geared to attract aspiring researchers, teachers, and specialists, with some other kind of doctoral degree for administrators and general practitioners.

Since the library field is broad and since, like any other profession, it encompasses a workaday world somewhat removed from its research world, surely there is room for both types. This adds a greater rather than a lesser burden to the library school's work, but it is also more realistic. The master's degree program provides the basic general education; a non-Ph.D. doctoral degree would provide competent administrative leadership, while a Ph.D. would produce scholars to extend and amplify the research base necessary for progress in the field. On the doctoral level, this is roughly like the division in modern physics between theoreticians and experimentalists.

Library science has progressed to the point where it can support specialists. Now it behooves the schools to produce them, and at the same time continue to turn out high-level administrative personnel. The same program is neither desirable nor necessary for both types.

\section{REFERENCES}

1. Phyllis A. Richmond, "The Subject Ph.D. and Librarianship," College \& Research Libraries 28:123-26, 146 (March 1957).

2. The proposal made here is partially accomplished by the Ph.D./D.L.S. programs at the University of California at Berkeley. The distinction between "academic" and "professional" seems apt. For an interesting discussion, see Margaret Monroe et al., "Reflections on the Doctoral Program," Journal of Education for Librarianship v. 8, no. 4 (Spring 1968) :251-82. 